university and beyond, as much as possible of the planning should be done by the committee as a whole. The Preparatory Commission is still awaiting the ratification, or at least the acceptance, of its charter by a sufficient number of Governments, before the secretariat can move to its permanent headquarters in Paris. Great Britain and Belgium have already accepted the constitution of the United Nations Educational, Scientific and Cultural Organisation, and the United States are expected to do so in the very near future.

A 'UNESCO Month', during which lectures, exhibitions, films, etc., would emphasize the value of international cultural co-operation, has been agreed upon as an important early feature by the United Nations Educational, Scientific and Cultural Organisation; it is to precede the annual conference which, according to its constitution, the Organisation must arrange every year in a different country. These meetings will be organised to bring about the right atmosphere in the host country, and to provide discussion at the highest level on current intellectual and spiritual problems. The host country would be stimulated to mobilize its best intellectual and artistic resources to enable the Conference to start its proceedings in a spirit attuned to the nature of its task. It is not intended that this 'UNESCO Month' should deal exclusively with the culture of the host country; leading authorities in other countries would no doubt co-operate in this work of international understanding. This scheme, which was put forward by Sir Alfred Zimmern, was approved by the Preparatory Commission. The first 'UNESCO Month' will probably be held in Paris next autumn.

\section{Biological Risks of Atomic Fission}

AN interesting and possibly very important biological problem has been emphasized by Dr. B. P. Wiesner (Lancet, 33, Jan. 5, 1946). Referring to the account of American work on the development of means of using atomic energy for military purposes, written by Prof. H. D. Smyth (H.M. Stationery Office, 1945), Dr. Wiesner points out that the questions involved are not merely political and social, as this report suggests, but are biological problems which cannot be solved by political or social control. The use of nuclear fission on a large scale, even if it be used only for industrial purposes, involves the important biological effects of the intense radioactivity which is produced by nuclear fission. Protective measures were adopted in the American plants, and similar measures will be required if nuclear fission is used for industrial purposes. Dr. Wiesner, however, urges that there are other effects which have not been adequately considered. Radiation may affect the gametes and their development; it does not necessarily prevent spermatogenesis or fertilization, but it may cause early fotal death. It may also cause genetic changes which have been studied in insects. The possibility of the occurrence of this kind of effect should, Dr. Wiesner urges, be discussed in public and not only by committees of experts briefed by their governments. The public must be allowed to have all the information that any expert can give. It will then be able to decide whether it will allow the application of nuclear fission to industry.

Dr. Wiesner's letter is followed by another by Mr. Kenneth Walker (Lancet, 69, Jan. 12, 1946), whose surgical experience and association with Dr. Wiesner in the study of male infertility will ensure adequate consideration of his views. We are, he reminds us, planning to make use of a force which has a profound influence on living tissues and more particularly on the cells responsible for the continuation of the race; and there is no excuse for postponing the study of the effects of this force. Much work has been done on the effects of $\mathrm{X}$-rays and radium on tissue cultures and on the structure of the testes, and on the protection of workers against these effects; but hospitals use only a few milligrams of radium, while the radioactive material produced by nuclear fission will be the equivalent of thousands of grams of radium. Mr. Walker also raises another important and related question. He is not satisfied that the possible reasons for the known high incidence of sub-fertility in otherwise healthy males have been adequately investigated. He finds it difficult to account for this sub-fertility without postulating the existence of some undiscovered factor in our industrial civilization which injures the germ-plasm. He therefore urges that the medical profession should not wait until the industrialists have completed their plans before it starts to study the possible biological consequences of the industrial use of atomic energy. This investigation is surely not a responsibility of the medical profession only. It is a public responsibility of other biologists also to find out whether risks to the continuance of the human race are involved and, if any are, to give the public all the information about them that can be obtained.

Theoretical Physics at Oxford: Prof. M. H. L. Pryce

Prof. M. H. L. Pryce, fellow of Trinity College, Cambridge, has been appointed to the newly reconstituted Wykeham chair of theoretical physics in the University of Oxford; he will take up the appointment next Trinity term. Prof. Pryce was educated at Cambridge, and later spent three years at the Institute of Advanced Studies, Princeton, with a Commonwealth fellowship. During the first part of the War he worked under the Admiralty in the Signal Establishment, later being transferred to Montreal to work with the 'Directorate of Tube Alloys'. His publications before the War included papers on non-linear electrodynamics, and Dirac's theory of radiation.

\section{Industrial Metallurgy at Birmingham : Appointment of Dr. Leslie Aitcheson}

A CHAIR of industrial metallurgy established at the University of Birmingham has been filled by the appointment of Dr. Leslie Aitcheson. Hitherto, the Department of Metallurgy has been mainly concerned with the production of men trained for research in the subject. Now the position is changing some. what. To quote from the Vice-Chancellor: "The development of manufacturing processes, recently an art, has now become an exact science and calls for men of the highest ability, who are needed at all levels of the modern manufacturing business, in administration, in all branches of production, management and control. Such men are necessary if the results of research are to be used effectively in the production of metals and alloys of the requisite quality at an economic price". Such men would have the same basic training as those intended for research as a career, but in addition they must be introduced to aspects of manufacture that have not hitherto been dealt with in degree courses in metallurgy. Dr. Aitcheson, who was educated at the University of Sheffield, has had wide practical experience, having 
been engaged, among other activities, as consulting metallurgist to the Air Ministry, the Association of Drop Forgers and Stampers, and various motor firms in the Birmingham district. In addition, he has written extensively on metallurgical subjects. The creation of the chair has been welcomed by many leading industrialists.

\section{Chemistry at University College, Leicester: Prof. L. Hunter}

As a consequence of the recognition of University College, Leicester, by the University Grants Committee, the College Council is proceeding to strengthen the teaching staff by the appointment of professors and additional lecturers. Among a number of appointments is that of Dr. L. Hunter to the chair of chemistry. That chemistry should be chosen for one of the first professorships to be established at Leicester is a tribute to Dr. L. Hunter's work as head of the Chemistry Department. Appointed in 1925 to found the Department, Dr. Hunter devoted his first years in Leicester to establisbing and consolidating it. Even during those difficult years, and working under a heavy burden of teaching, he never lost sight of the value and importance of research work in any virile teaching department. In translating this ideal into a reality, Dr. Hunter met many difficulties, not the least being the lack of postgraduate scholarships in so young a college. Surmounting these in many novel ways, Dr. Hunter succeeded in establishing a vigorous and steadily growing research school which consisted, immediately prior to the War, of some ten post-graduate research workers. In this work he was loyally supported by his first assistant, Dr. A. Hickling, who is now lecturer in electrochemistry in the University of Liverpool. Even during the difficult years of war, Dr. Hunter's department maintained a steady though reduced output of original work. Dr. Hunter and his co-workers have made important contributions to the chemistry of the hydrogen bond, particularly as it concerns molecular association and tautomerism, and to the chemistry of chelate metallic derivatives of organic compounds. Coming to Leicester from the University College of North Wales, Bangor, he was versed in the traditions of the late Prof. Kennedy Orton's school of chemistry, and his earlier published work concerned the use of chloroamines in the stepwise halogenation of organic compounds.

\section{Exhibition of German Aeronautical Developments}

THE exhibition of German aeronautical developments, with which the Science Museum, South Kensington, is re-opened, is the result of the great interest taken in a much larger one held at the Royal Aircraft Establishment, Farnborough, during the autumn of 1945. This was confined to invited guests, for obvious reasons, and although these invitations were very widely distributed it was felt that there was still a number of students of aeronautics, in its various aspects, who could profit by it. Limitation of space has necessitated reducing the exhibits, especially the complete aircraft, but as wide a choice in types as possible has been made. Many of the exhibits are sectioned and shown in the 'exploded' form, liberally supplied with explanatory show cards. There are a few exhibits of British work by way of comparison, and an excellent display of photographs, arranged comparatively, German and British.

The aircraft range from gyro-controlled kites, pilotless aircraft, rockets, to the small fighter aircraft.
The engine section has various types of piston engines, and a comprehensive display of gas turbines and jet propulsion units in several forms. Instruments and general equipment occupy some of the galleries, and there is a special display of aireraft armament. The general layout of the exhibition is well thought out, and it should be of great help to the student of aeronautics, who has necessarily not had the opportunity of keeping abreast of the developments in the many different aspects of the science during the war period. A catalogue is available that is not only a guide but also contains much technical information supplementing that given on the show cards. The catalogue invites further inquiries from anyone genuinely interested, which will be answered, so far as further data is available, by the Director, Royal Aircraft Establishment, South Farnborough, Hants.

\section{'Flavazole', an Effective New Antiseptic}

YET another new series of compounds has been added to the growing list of antiseptics. Prof. J. MeIntosh and his collaborators (Lancet of July 28, p. 97) report upon their trials of 'Flavazole', which is a chemical combination, in equimolecular proportions, of sulphathiazole and proflavine base. This represents a new type of acridine compound, which has been introduced by the research laboratories of Messrs. Boots Pure Drug Co., Ltd., and it is claimed to be an advance on the mixtures of one part of proflavine and 99 parts of sulphathiazole, widely used in powder form in the Army and in industry for the first-aid treatment of wounds. These new compounds are neutral or slightly alkaline in solution and are less irritant than their acridine components. In vitro tests have shown that they "have lost none of the bacteriostatic powers of their components". Comparison of the action of 'Flavazole', sulphathiazole and proflavine upon "all types of organisms likely to be found in wounds" (including the Clostridia which cause gas gangrene) shows that the bacteriostatic power of 'Flavazole' is greater than that of either of its components, especially against Gram-negative bacilli. It has slightly more activity against $P$ seudomonas pyocyanea and Proteus.

Clinical trials of 'Flavazole' have shown that it can be safely used in the conjunctival sac and in any infected cavity as a wound antiseptic. Used as a powder composed of 2 per cent 'Flavazole' and 98 per cent of sulphathiazdle, it will control mixed infections in wounds. Dusting with this powder led to the disappearance of bacteria within three days. The severe test of treatment in a spinal unit of pressure sores and other wounds which were heavily infected with pyogenic cocci and Gram-negative bacilli showed that 'Flavazole' greatly reduced these infections. 'Flavazole' is not irritating, and is safer than proflavine. The dilution of penicillin with the powder just mentioned provides "a highly-potent antibacterial power with a wide range of activity against all bacteria likely to be found in wound sepsis".

\section{Conference on Fundamental Particles and Low Temperature Physics}

Tне Physical Society, in collaboration with the Cavendish Laboratory, is holding a conference at Cambridge under the combined title of "Funda. mental Particles" and "Low Temperature Physics" during July 22-27. One day of the conference is to be devoted to the formal opening of the new Austin Wing of the Cavendish Laboratory, and to lectures 